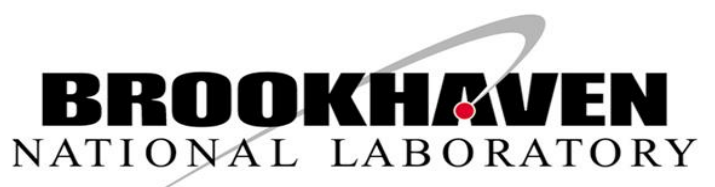

BNL-114443-2017-JA

\title{
Mesoporous Polymer Frameworks from End-Reactive Bottlebrush Copolymers
}

\author{
J. Rzayev, D. Nykypanchuk
}

Submitted to ACS Nano

August 2017

Center for Functional Nanomaterials

Brookhaven National Laboratory

\author{
U.S. Department of Energy \\ USDOE Office of Science (SC), \\ Basic Energy Sciences (SC-22)
}

\footnotetext{
Notice: This manuscript has been authored by employees of Brookhaven Science Associates, LLC under Contract No. DE- SC0012704 with the U.S. Department of Energy. The publisher by accepting the manuscript for publication acknowledges that the United States Government retains a nonexclusive, paid-up, irrevocable, world-wide license to publish or reproduce the published form of this manuscript, or allow others to do so, for United States Government purposes.
} 


\section{DISCLAIMER}

This report was prepared as an account of work sponsored by an agency of the United States Government. Neither the United States Government nor any agency thereof, nor any of their employees, nor any of their contractors, subcontractors, or their employees, makes any warranty, express or implied, or assumes any legal liability or responsibility for the accuracy, completeness, or any third party's use or the results of such use of any information, apparatus, product, or process disclosed, or represents that its use would not infringe privately owned rights. Reference herein to any specific commercial product, process, or service by trade name, trademark, manufacturer, or otherwise, does not necessarily constitute or imply its endorsement, recommendation, or favoring by the United States Government or any agency thereof or its contractors or subcontractors. The views and opinions of authors expressed herein do not necessarily state or reflect those of the United States Government or any agency thereof. 


\title{
Mesoporous Polymer Frameworks from End-Reactive Bottlebrush Copolymers
}

\author{
Esra Altay ${ }^{1}$, Dmytro Nykypanchuk ${ }^{2}$, and Javid Rzayev ${ }^{1, *}$ \\ ${ }^{1}$ Department of Chemistry, University at Buffalo, The State University of New York, Buffalo, New \\ York 14260-3000, United States \\ ${ }^{2}$ Center for Functional Nanomaterials, Brookhaven National Laboratory, Upton, New York \\ 11973, United States
}

*Email: jrzayev@buffalo.edu 


\begin{abstract}
Reticulated nanoporous materials generated by versatile molecular framework approaches are limited to pore dimensions on the scale of the utilized rigid molecular building blocks $(<5 \mathrm{~nm})$. The inherent flexibility of linear polymers precludes their utilization as long framework connectors for the extension of this strategy to larger length scales. We report a method for the fabrication of mesoporous frameworks by using bottlebrush copolymers with reactive end blocks serving as rigid macromolecular interconnectors with directional reactivity. End-reactive bottlebrush copolymers with pendant alkene functionalities were synthesized by a combination of controlled radical polymerization and polymer modification protocols. Ru-catalyzed crossmetathesis cross-linking of bottlebrush copolymers with two reactive end blocks resulted in the formation of polymer frameworks where isolated cross-linked domains were interconnected with bottlebrush copolymer bridges. The resulting materials were characterized by a continuous network pore structure with average pore sizes of $9-50 \mathrm{~nm}$, conveniently tunable by the length the utilized bottlebrush copolymer building blocks. The materials fabrication strategy described in this work expands the length scale of molecular framework materials and provides access to mesoporous polymers with a molecularly tunable reticulated pore structure without the need for templating, sacrificial component etching, or supercritical fluid drying.
\end{abstract}

Keywords: nanoporous materials, polymer networks, bottlebrush copolymers, organic frameworks, cross-linking 
Nanoporous solids have found widespread use in numerous applications, such as catalysis, gas storage, and separations. ${ }^{1-5}$ A diverse collection of top-down and bottom-up synthetic methods has been employed to generate such materials with emphasis on controlling various structural characteristics, such as pore size and distribution, pore volume, surface area, chemical functionality, and mechanical properties, that facilitate their utilization in specific applications. One of the most powerful and elegant ways of constructing porous solids has been through the use of rigid molecular building blocks with directional interactions, which allows for the formation of extended networks through rational molecular design strategies. An impressive array of crystalline and amorphous porous solids, such as metal organic frameworks (MOFs), ${ }^{6,7}$ covalent organic frameworks (COFs), ${ }^{8}$ and polymers with intrinsic microporosity (PIMs), ${ }^{9}$ has been fabricated by covalent and noncovalent assembly of small rigid molecular fragments with limited conformational freedom. Owing to the reliance of these methods on small molecular building blocks, the generated porous solids have been typically restricted to pore sizes of less than $5 \mathrm{~nm}$. Extending similar molecular design principles for the fabrication of larger length scale porous frameworks, poised to facilitate a gamut of new applications, is a fascinating proposition but a daunting challenge due to the lack of suitable building blocks. Herein, we describe the design and preparation of mesoporous polymer frameworks (MPFs), a class of porous materials with nanotruss-like morphology constructed from rigid macromolecular interconnectors with brush-like architecture and directional connectivity.

The search for larger molecular building blocks that can advance molecular design principles of MOFs and COFs to a different length scale inevitably leads to synthetic polymers, which provide a robust, chemically tunable and inexpensive platform for materials fabrication. However, due to the inherent flexibility of linear macromolecules, they cannot serve as rigid network 
interconnectors required for the construction of molecular frameworks. Therefore, we chose to use bottlebrush copolymers, characterized by a tunable molecular stiffness and persistent cylindrical shape, as rigid macromolecular network bridges. Bottlebrush copolymers are an emerging class of branched macromolecules with a comb-like architecture where excluded volume interactions between densely grafted side chains force the backbone to adopt an extended conformation. ${ }^{10,11}$ Persistence length of cylindrical bottlebrush copolymers with acrylic side chains has been reported to be $35 \mathrm{~nm}$ even for relatively short side chains. ${ }^{12}$ Additionally, intramolecular cross-linking of side chains can provide even stiffer cylindrical objects, suitable, for example, for the formation of standalone organic nanotubes. ${ }^{13-15}$ Network bottlebrush copolymer materials obtained by random chemical cross-linking through bottlebrush side chains have been recently reported for the fabrication of supersoft elastomers ${ }^{16,17}$ and nanoscale networks. ${ }^{18}$ While these new and exciting materials offer some unique attributes, they lack the directional connectivity necessary for the formation of uniform molecular frameworks through rational molecular design principles. In this report, we disclose a template-free strategy for the formation of polymer frameworks through the use of reinforced bottlebrush copolymer interconnectors with reactive end blocks, which enables controlled network buildup by selective end-to-end attachment (Figure 1). We demonstrate that the produced mesoporous polymer frameworks boast uniform pore dimensions that can be controlled through judicious manipulation of the molecular structure of bottlebrush interconnectors. Bottlebrush macromolecular building blocks and the template-free network design platform developed in this work expand the length scale, functionality and utility of organic framework materials. 

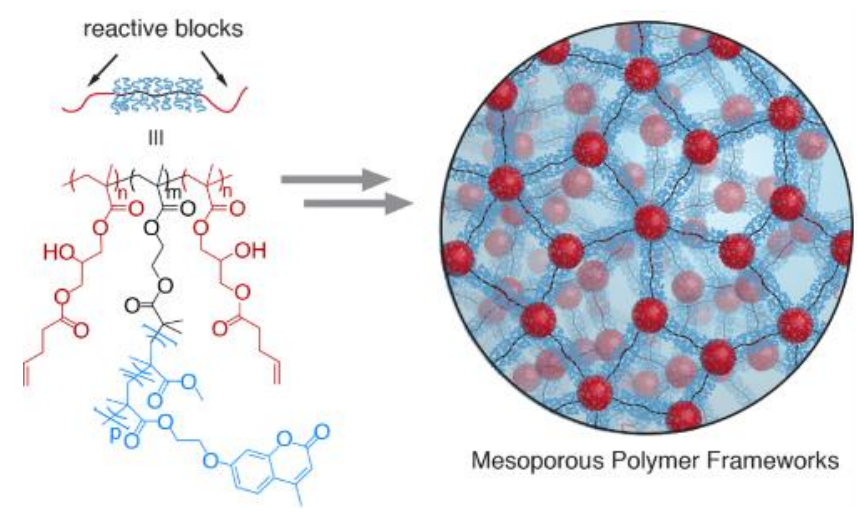

Figure 1. Construction of mesoporous polymer frameworks from shape-persistent bottlebrush copolymers with reactive end blocks.

\section{Results and Discussion}

Bottlebrush interconnectors were engineered to possess several important attributes to allow for their utilization in controlled fabrication of mesoporous frameworks. In order to avoid random side chain cross-linking and promote controlled network buildup, reactive linear end blocks containing olefinic pendant groups were installed at both ends of bottlebrush copolymers. Crossmetathesis reaction between double bonds of different linear end blocks was used as the network formation chemistry. The bottlebrush side chains were decorated with photo-cross-linkable coumarin groups ${ }^{19}$ for intramolecular reinforcement of rigid cylindrical network interconnectors. The inherent stiffness of the bottlebrush middle block should also minimize the loop formation, where both reactive end blocks reside within the same junction point, which diminishes the structural integrity and mechanical properties of the polymer networks.

Bottlebrush copolymers with controlled dimensions and orthogonally cross-linkable functionalities (Figure 1) were synthesized by a grafting-from method using reversible activationdeactivation radical polymerization methods (Supporting Information). Briefly, a linear triblock 
copolymer backbone was prepared first by reversible addition-fragmentation chain transfer polymerization ${ }^{20}$ to contain end blocks with epoxide functionalities and the middle block with activated bromide groups. ${ }^{21}$ Bottlebrush side chains were then installed from the middle block by atom transfer radical copolymerization ${ }^{22,23}$ of methyl methacrylate (MMA) and a coumarincontaining methacrylate $(\mathrm{CMA})$ monomer $(\mathrm{MMA} \mathrm{CMA}=1.3-1.7)$. Finally, olefinic functionalities were introduced into the linear end blocks by reaction of pendant epoxide groups with 4-pentenoic acid in the presence of triethylamine. ${ }^{1} \mathrm{H}$ NMR analysis revealed near complete conversion (87-97\%) of epoxide groups to pendant olefins (see Supporting Information Figure S2). A series of reactive triblock bottlebrush copolymers with constant length linear end blocks (85-110 units) and varying side chain and backbone lengths of the middle bottlebrush block were synthesized and exploited for network formation (Table S1, Supporting Information).

The synthesis of isolated junction points from bottlebrush copolymers with one reactive end block was performed first (Figure 2) in order to evaluate the efficacy of the cross-linking chemistry as this allowed for the solution characterization of the formed star-brush copolymers. We previously reported the formation of star-brush copolymers using amine-epoxide coupling chemistry; ${ }^{21}$ however, that method was slow (5 days to completion) and was found to be unsuitable for network formation. Instead, we utilized powerful olefin cross-metathesis chemistry ${ }^{24-26}$ promoted by the second generation Grubbs' catalyst to connect giant bottlebrush molecules together. Size exclusion chromatography (SEC) analysis of the cross-linking reaction revealed fast and efficient formation of star-brush copolymers (junction points), which was evidenced by almost complete disappearance of the reactive bottlebrush precursor signal and the appearance of a new peak at lower elution volume (larger size) attributed to the newly formed star-brush copolymers. The cross-linking was completed within a few hours irrespective of bottlebrush side chain 
dimensions. From SEC data, we also calculated the average number of bottlebrush arms emanating from each star core to be 10 for both samples. Additionally, no macroscopic gelation or high molecular weight shoulders were observed for the star-brush peak in SEC indicating the formation of standalone junction points as the brush block provided enough steric shielding to allow crosslinking to proceed within isolated domains. Thus, the chosen length of the linear end blocks enabled efficient end-to-end bottlebrush connectivity without coupling of the cross-linked junction domains. The latter is important for the controlled formation of mesoporous frameworks where individual network junction points are interconnected with bottlebrush bridges of similar length.

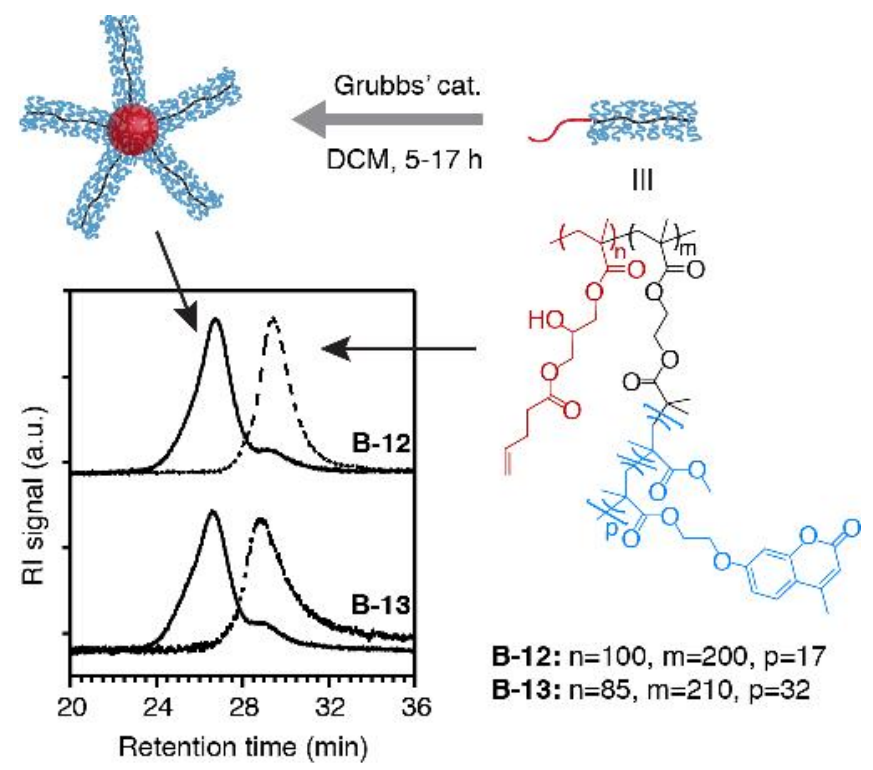

Figure 2. Efficient synthesis of star-brush copolymers (isolated junction points) from bottlebrush copolymers with one reactive end block.

Mesoporous polymer frameworks were produced by cross-linking bottlebrush copolymers with two reactive linear end blocks dissolved in a dichloromethane (DCM) solution at 20-30 wt $\%$ concentrations. Dual cross-linking was performed by using Grubbs' catalyst to promote coupling of the reactive end blocks and network formation, and subsequent photo-cross-linking of bottlebrush side chains via [2+2] dimerization of pendant coumarin groups for bridge 
reinforcement. A simple solvent exchange with $N, N$-dimethylformamide (DMF) and water and drying under vacuum of the bottlebrush gels resulted in lightweight nanoporous monoliths. Scanning electron microscopy analysis of MPFs provided a stunning evidence for the formation of reticulated morphologies where three-dimensional polymer frameworks were held together by individual bottlebrush interconnectors (Figure 3). The thickness of individual strands connecting the junction points was measured to be 10-15 nm (taking into account 1-2 nm gold coating used during scanning electron microscopy SEM sample preparation), consistent with the expected diameter of the bottlebrush copolymer precursor. Some thicker strands were also present, which can be attributed to bundles of two or three bottlebrush molecules forming a single bridge.
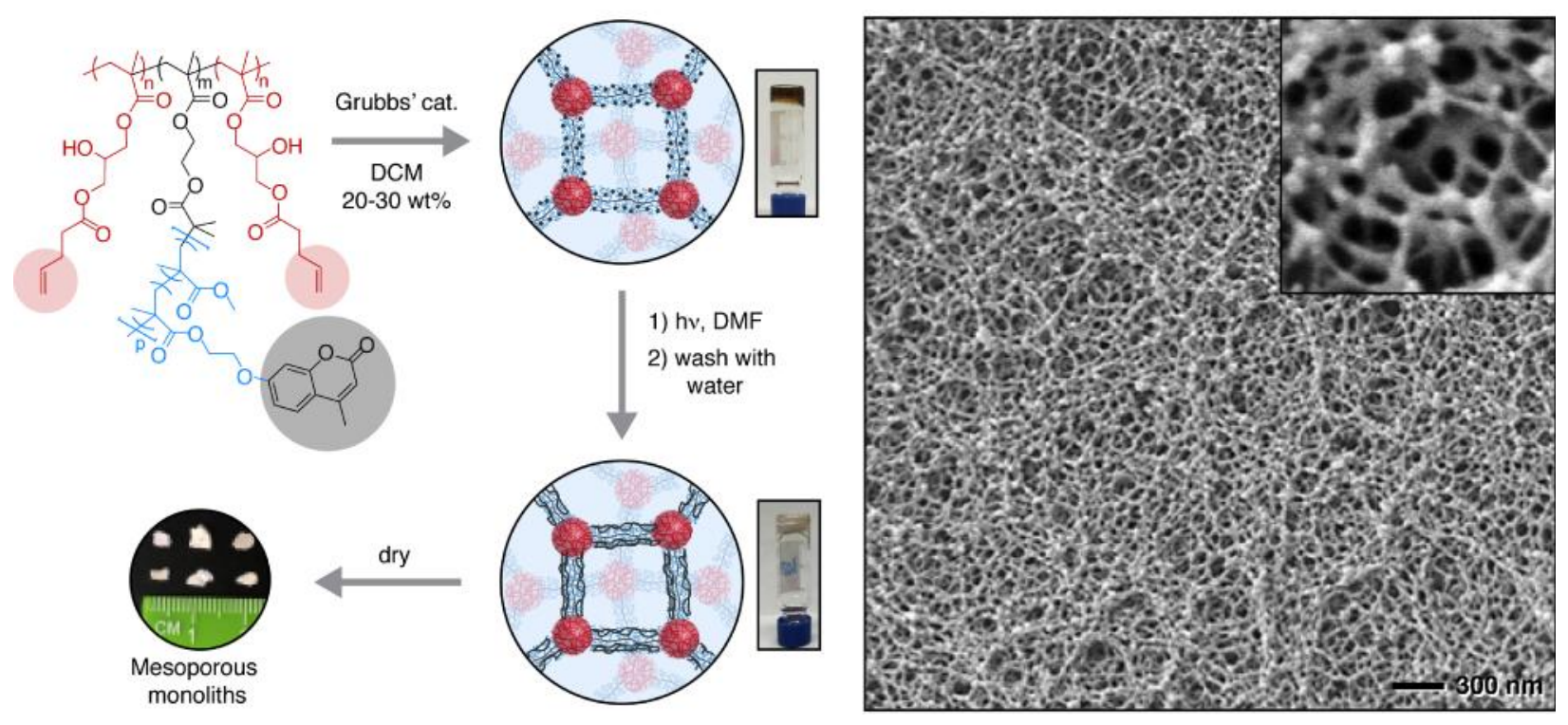

Figure 3. Synthesis of mesoporous monoliths from end reactive bottlebrush copolymer precursors and a large-area scanning electron micrograph of MPF-11. The inset is shown in a $400 \times 400 \mathrm{~nm}^{2}$ box. 
Table 1. Structural Characterization of Mesoporous Polymer Frameworks

\begin{tabular}{lcccccccc}
\hline sample & $\begin{array}{c}\text { polymer } \\
\text { precursor }^{\mathrm{c}}\end{array}$ & $N_{\text {backb }^{\mathrm{d}}}$ & $\begin{array}{c}N_{\text {side chain }} \\
(\mathrm{CMA} / \mathrm{MMA})^{\mathrm{e}}\end{array}$ & $\begin{array}{c}M_{\mathrm{n}} \\
(\mathrm{kg} / \mathrm{mol})^{\mathrm{f}}\end{array}$ & $\begin{array}{c}S_{\text {BET }} \\
\left(\mathrm{m}^{2} / \mathrm{g}\right)^{\mathrm{g}}\end{array}$ & $\begin{array}{c}d_{\text {pore,BJH }} \\
(\mathrm{nm})^{\mathrm{h}}\end{array}$ & $\begin{array}{c}V_{\text {pore }} \\
(\mathrm{mL} / \mathrm{g})^{\mathrm{i}}\end{array}$ & $\begin{array}{c}\text { porosity } \\
(\%)^{\mathrm{j}}\end{array}$ \\
\hline MPF-1 $^{\mathrm{a}}$ & B-1 & 390 & $12 / 18$ & 2192 & 73 & 36 & $0.84(0.67)$ & 46 \\
MPF-2 $^{\mathrm{a}}$ & B-2 & 420 & $7 / 10$ & 1413 & 83 & 44 & $0.87(0.61)$ & 47 \\
MPF-3 $^{\mathrm{a}}$ & B-3 & 190 & $15 / 26$ & 1400 & 110 & 31 & $0.91(0.83)$ & 48 \\
MPF-4 $^{\mathrm{a}}$ & B-4 & 210 & $8 / 13$ & 864 & 100 & 25 & $0.92(0.81)$ & 48 \\
MPF-5 $^{\text {a }}$ & B-5 & 210 & $4 / 7$ & 496 & 80 & 21 & $0.57(0.52)$ & 36 \\
MPF-6 $^{\text {a }}$ & B-6 & 130 & $9 / 12$ & 565 & 89 & 21 & $0.42(0.40)$ & 30 \\
MPF-7 $^{\mathrm{a}}$ & B-7 & 130 & $6 / 8$ & 403 & 87 & 16 & $0.46(0.44)$ & 32 \\
MPF-8 $^{\mathrm{a}}$ & B-8 & 130 & $4 / 5$ & 291 & 101 & 14 & $0.60(0.55)$ & 38 \\
MPF-9 $^{\mathrm{a}}$ & B-9 & 80 & $5 / 8$ & 249 & 96 & 9 & $0.43(0.39)$ & 30 \\
MPF-10 $^{\mathrm{b}}$ & B-3 & 190 & $15 / 26$ & 1400 & 73 & 72 & $1.13(0.44)$ & 53 \\
MPF-11 $^{\mathrm{b}}$ & B-4 & 210 & $8 / 13$ & 864 & 124 & 42 & $1.27(0.98)$ & 56 \\
MPF-12 $^{\mathrm{b}}$ & B-6 & 130 & $9 / 12$ & 565 & 113 & 30 & $0.95(0.89)$ & 49 \\
MPF-13 $^{\mathrm{b}}$ & B-10 & 130 & $4 / 6$ & 304 & 120 & 25 & $0.99(0.91)$ & 50 \\
MPF-14 $^{\mathrm{b}}$ & B-11 & 80 & $9 / 13$ & 385 & 134 & 29 & $0.59(0.52)$ & 37 \\
\hline
\end{tabular}

${ }^{\mathrm{a}}$ Monoliths prepared using an initial polymer concentration of $30 \mathrm{wt} \%$.

${ }^{b}$ Monoliths prepared using an initial polymer concentration of $20 \mathrm{wt} \%$.

${ }^{\mathrm{c} B o t t l e b r u s h}$ copolymer used as framework connector from Table S1.

${ }^{\mathrm{d}}$ Average number of repeat units per bottlebrush backbone.

${ }^{\mathrm{e} A v e r a g e ~ n u m b e r ~ o f ~ r e p e a t ~ u n i t s ~ p e r ~ b o t t l e b r u s h ~ s i d e ~ c h a i n . ~}$

fTotal molecular weight of bottlebrush copolymer precursors.

'Surface areas calculated from nitrogen adsorption isotherms using the BET equation.

${ }^{\mathrm{h}}$ Median pore diameters calculated from nitrogen adsorption data using the $\mathrm{BJH}$ method.

${ }^{i}$ Pore volumes calculated from nitrogen adsorption data using the BJH method, and pore volumes calculated using the DFT slit/cylinder pore equilibrium model (in parentheses).

${ }^{j}$ Porosity calculated from BJH pore volumes assuming a polymer density of $1 \mathrm{~g} / \mathrm{cm}^{3}$.

Nitrogen adsorption analysis ${ }^{27}$ of the monoliths revealed typical type IV isotherms, indicating the formation of mesoporous materials (Figure 4a). As summarized in Table 1, MPFs were characterized by Brunauer-Emmet-Teller (BET) surface areas of 73-134 m²/g and Barrett-JoynerHalenda (BJH) pore volumes of $0.42-1.27 \mathrm{~mL} / \mathrm{g}$, corresponding to $30-56 \%$ porosities. BJH pore volumes were calculated assuming straight cylindrical pores. Using a pycnometer, densities for 
samples MPF-5, MPF-10, and MPF-14 were measured to be $0.17,0.26$, and $0.26 \mathrm{~g} / \mathrm{mL}$, respectively, corresponding to $74-83 \%$ porosities. Pore diameters calculated by the $\mathrm{BJH}$ method were in the range of 9-50 nm with relatively narrow pore size distributions for MPFs formed at 30 wt $\%$ initial concentration (Table 1 and Figure $4 b$ ). The latter is remarkable given the irreversible nature of the chemical cross-linking process that is responsible for network formation. The obtained MPF pore size distributions were comparable to the reported BJH pore size distributions of ordered mesoporous networks derived from block copolymer precursors. ${ }^{28}$ The exclusive formation of mesoporosity is in contrast to nanoscale networks formed by random side chain crosslinking of bottlebrush copolymers, which were reported to contain a combination of micro-, mesoand macropores. ${ }^{18} \mathrm{MPFs}$ were thermally stable up to $125^{\circ} \mathrm{C}$, at which temperature an irreversible exothermic transition was observed on the first heating cycle by differential scanning calorimetry (Figure S5, Supporting Information), which was attributed to the softening of polymer bridges and pore collapse with the corresponding release of surface energy, consistent with thermal analyses of other mesoporous polymeric materials. ${ }^{29}$ The pore collapse occurred in the proximity of the glass transition temperature of cross-linked bottlebrush strands, which was measured to be $128^{\circ} \mathrm{C}$ from DSC analysis of the cross-linked star brushes (Supporting Information, Figure S5).

Pore dimensions obtained from the BJH data were corroborated by SEM analysis. Using image analysis of scanning electron micrographs of samples MPF-8 and MPF-4, we calculated average pore diameters of $14 \pm 6$ and $31 \pm 10 \mathrm{~nm}$, respectively, which matched the numbers obtained from $\mathrm{BJH}$ analysis of nitrogen adsorption data (Table 1). When plotted on the same $\mathrm{x}$-axis, pore size distributions obtained from SEM analysis were also in close agreement with BJH data (Figure 4c). Thus, we took BJH pore diameters and size distributions to be good approximations of network dimensions and uniformity, despite various assumptions that go into BJH data analysis. 

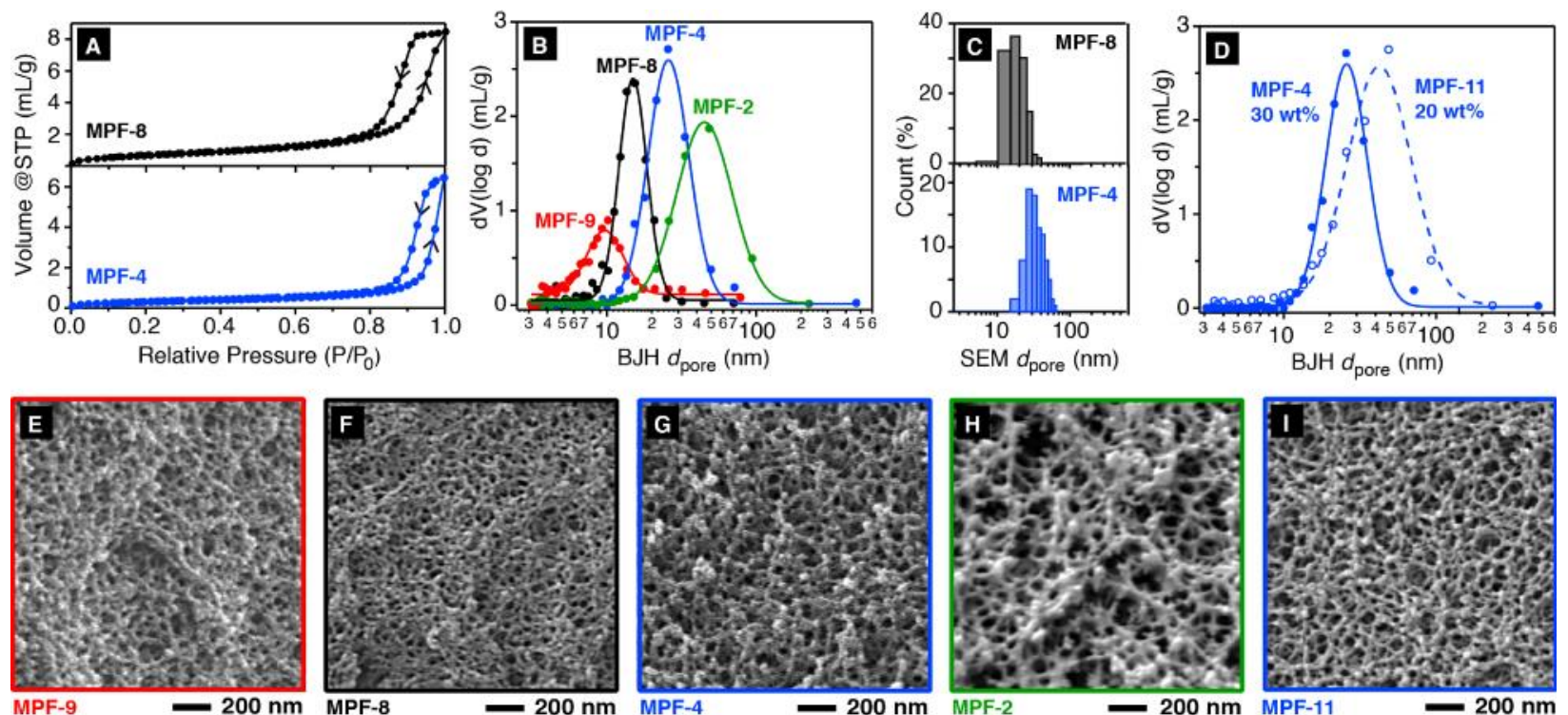

Figure 4. Nitrogen adsorption and SEM analyses of mesoporous polymer frameworks: (A) nitrogen adsorption isotherms, (B) BJH pore size distribution calculated from nitrogen adsorption data of MPFs prepared at $30 \mathrm{wt} \%$, (C) SEM pore size distribution, (D) BJH pore size distribution comparison between MPFs prepared from the same polymer precursor B-4 at 30 and $20 \mathrm{wt} \%$ and corresponding SEM images (E-I).

The porosity of the sample should also reveal itself in the small angle X-ray scattering (SAXS) measurements. Figure S6 (Supporting Information) shows SAXS profiles for samples MPF-4 and MPF-9 (curves are shifted for clarity). Qualitatively both samples show the presence of polydisperse scatterers at tens of nanometer length scales ( $q$ range $\sim 0.01-0.04 \mathrm{~A}^{-1}$ ) with sharp interfaces as indicated by the -4 exponent at larger $q$ values, which likely represents scattering from the pores in the material. Consistent with porosity measured by SEM and BJH, MPF-9 is showing smaller size scatterers than MPF-4. The upturn in intensity at lower $q$ values is likely due to the presence of material grains on a micrometer length scale and does not pertain to our discussion. To analyze the data more quantitatively, we modeled scattering using a Gaussian distribution of cylinders with equal aspect ratios and interference effect ${ }^{30}$ to represent pores in the material and Gaussian population of noninterfering spherical particles to account for material 
grains at the micrometer length scale. Modeling has been done using the Irena package for IgorPro. ${ }^{30}$ The best fits for MPF-9 and MPF-4 samples were obtained by using cylinders with mean diameters of 12.6 and $19.4 \mathrm{~nm}$ and interference length scales of 22.5 and $35.7 \mathrm{~nm}$, respectively. These numbers are consistent with pore and structure dimensions obtained from nitrogen adsorption and SEM morphological analysis.

The majority of the gelation experiments were conducted for solutions of bottlebrush copolymers in dichloromethane at the initial concentration of $30 \mathrm{wt} \%$. This was the highest practically achievable concentration and thus led to the formation of the densest and most uniform networks. When the initial polymer concentration was reduced to $20 \mathrm{wt} \%$, the obtained MPFs exhibited higher surface areas, higher pore volumes, larger pore diameters, but much broader pore size distributions than their counterparts prepared at $30 \mathrm{wt} \%$ (Table 1). These results are indicative of the formation of loose and irregular networks at lower polymer concentrations. The comparison between BJH pore size distribution curves of MPFs prepared from the same polymer precursor at different initial concentrations (MPF-4 vs MPF-11) revealed significant broadening toward larger pore dimensions in $20 \mathrm{wt} \% \mathrm{MPF}-11$, while the lower end of the distribution remained the same (Figure 4d). This behavior is consistent with the fact that bottlebrush copolymer dimensions (independent of polymer concentration) dictate the smallest attainable pore diameters, while the higher end of pore size distributions is governed by cross-linking density, polymer concentration, and other factors. It appears that the onset pore diameter, $d_{\text {pore,onset, }}$ obtained by extrapolating the lower side of the distribution curve to the x-axis (Figure S7, Supporting Information), is not affected by small concentration changes and is a more meaningful network characterization parameter than the peak pore diameter obtained from $\mathrm{BJH}$ pore size distribution curves. Comparative SEM analysis of MPF-4 and MPF-11 corroborated the formation of a more porous 
and loosely connected network morphology for the sample prepared at $20 \mathrm{wt} \%$ concentration (Figure 4g,i).

Pore dimensions of the synthesized MPFs were predictably manipulated by the choice of the bottlebrush connectors. As can be seen from Figure 4b, MPFs with varying pore diameters were prepared from different bottlebrush copolymer precursors. Reticulated morphologies were evident in all samples irrespective of pore dimensions (Figure 4e-h). We used a three-dimensional correlation plot (Figure 5a) between the size of bottlebrush side chains (y-axis), the length of the bottlebrush backbones (x-axis), and MPF pore diameter (marker size and shade) for networks prepared at the initial polymer concentration of $30 \mathrm{wt} \%$ to demonstrate pore size variation trends. Using longer bottlebrush connectors resulted in MPFs with larger pore diameters, which was a reliable way of controlling the mesh size of the bottlebrush networks. The obtained median pore diameters of 9-44 $\mathrm{nm}$ and onset pore diameters of 5-18 nm for these MPFs are consistent with the length of utilized bottlebrush connectors, where end-to-end distances of the hypothetically fully stretched bottlebrush backbones are in the range of 20-110 nm (representing maximum connector length). For four MPFs prepared from bottlebrush connectors with varying backbone lengths but relatively similar side chain length (MPF-9,7,5,2), the onset pore diameters appeared to scale linearly with the logarithm of the backbone length $(d \sim \log N)$ (Figure $5 \mathrm{~b})$. While physical meaning behind this simple empirical relationship is unclear, it provides a convenient handle for predictable materials design. Side chain length variation produced more nuanced effects on pore dimensions due to competition between opposing trends of bottlebrush connector stiffening with increasing side chain lengths ${ }^{31}$ and volume filling. For middle length connectors, this resulted in a modest increase in pore diameters with increased side chain dimensions. The ability to manipulate network dimensions by a simple molecular design not only affords a versatile materials design platform but 
also evidences controlled network buildup through end block interactions rather than random side chain cross-linking or some phase inversion process during solvent exchange.
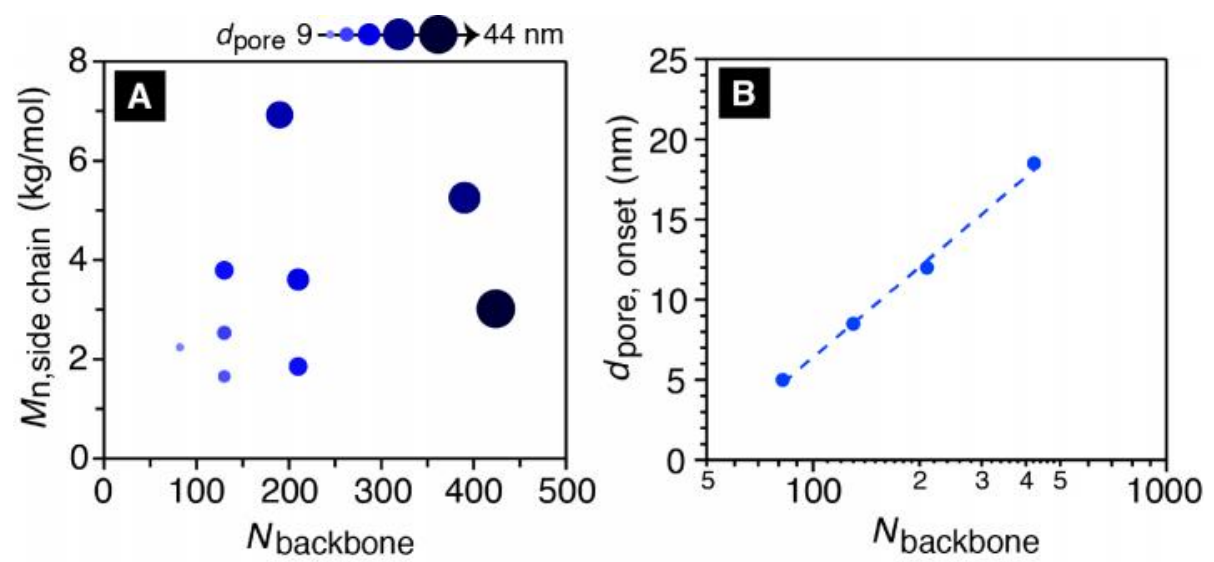

Figure 5. Analysis of MPF pore dimensions prepared at initial $30 \mathrm{wt} \%$ polymer concentration: (A) 3D correlation plot between bottlebrush side chain size (y-axis), bottlebrush backbone size (x-axis), and median BJH pore diameter (marker size and shade), and (B) linear relationship between BJH onset pore diameter and logarithm of backbone length for MPF prepared from bottlebrush copolymers with similar side chains and varying backbone dimensions.

The importance of photo-cross-linking of bottlebrush side chains was investigated by comparing MPFs prepared from the same precursor polymer in the presence or the absence of the UV irradiation step. Photo-cross-linking was conducted under conditions optimized for the starbrush system, where irradiation for $2 \mathrm{~h}$ at $365 \mathrm{~nm}$ led to complete disappearance of the coumarin UV absorbance peak at $320 \mathrm{~nm}$ (Figure S8, Supporting Information). The effect of photo-crosslinking was drastically different for short and long bottlebrush connectors. The control MPF prepared from the same short backbone polymer precursor as MPF-14 but without the photo-crosslinking step exhibited a similar surface area $\left(129 \mathrm{~m}^{2} / \mathrm{g}\right)$ and pore dimensions $(30 \mathrm{~nm})$. On the other hand, for a non-photo-cross-linked MPF prepared from the same long-backbone polymer as MPF- 
10, the BET surface area decreased from 73 to $32 \mathrm{~m}^{2} / \mathrm{g}$, BJH pore volume decreased from 1.13 to $0.22 \mathrm{~mL} / \mathrm{g}$, and pore diameter decreased from 72 to $31 \mathrm{~nm}$ compared to its photo-cross-linked analogue. While mesoporous materials can be prepared even without the photo-cross-linking step, the results are consistent with significant network shrinkage in its absence for longer backbone connectors. Therefore, we conclude that reinforcement of bottlebrush connectors by intramolecular cross-linking provides additional structural support for the fabrication of robust framework materials.

\section{Conclusions}

In summary, we developed a method for the fabrication of polymer frameworks with mesoscale domain sizes $(2-50 \mathrm{~nm})$. Giant bottlebrush copolymers with a comb-like architecture served as rigid interconnectors covalently linked together by selective cross-linking through reactive end blocks. Photo-cross-linking of bottlebrush copolymer side chains provided additional reinforcement especially for longer connector networks. The generated polymer gels were robust enough to withstand simple solvent exchange and evaporation to produce mesoporous polymer frameworks whose structural characteristics were dictated by molecular dimensions of the bottlebrush copolymer precursors, allowing for rational materials design strategies. MPFs prepared at high initial polymer concentrations of $30 \mathrm{wt} \%$ resulted in uniform pore size distributions and exhibited reticulated morphologies with pore diameters of 10-50 nm, which was found to scale logarithmically with the number of repeat units in the bottlebrush interconnector backbone. Mesoporous polymer frameworks developed in this work offer a unique combination of attributes that distinguishes them from other porous materials: (1) larger domain length scale compared to organic framework materials or PIMs prepared from small-molecule building blocks; (2) template- 
free access to network morphologies with uniform dimensions, alleviating the need for pore alignment for transport-based applications; ${ }^{32}$ (3) expanded range of accessible pore dimensions

and larger pore volumes compared to block copolymer based strategies; ${ }^{33,34}$ (4) no need for chemical etching or supercritical fluid drying to generate porosities. The materials design strategy disclosed here is well suited for exploring and developing highly ordered polymer framework materials with a potential ability to independently control network mesh size and mechanical properties for applications as membranes, catalyst supports, and lightweight engineering plastics.

\section{Methods}

Materials. Azobis(isobutyronitrile) (AIBN) was recrystallized from methanol and dried under vacuum before use, and dichloromethane (DCM) was dried using a commercial solvent purification system (Innovative Inc.). Glycidyl methacrylate (GM), and methyl methacrylate (MMA) were passed through a basic alumina column before polymerization to eliminate the radical inhibitor. Poly(glycidyl methacrylate) (PGM) homopolymer and poly((glycidyl methacrylate)- $b$-(2-(2-bromoisobutyryloxy)ethyl methacrylate)) (poly(GM- $b$-BIEM)) diblock copolymer were synthesized following the same procedures as reported in our previous study. ${ }^{21} 7$ (2-Hydroxyethoxy)-4-methylcoumarin $\quad(H E O M C)^{35}$ and 7-(2-methacryloyloxyethoxy)-4methylcoumarin $(\mathrm{CMA})^{36}$ were synthesized according to the literature procedures. All other chemicals were used as received unless stated otherwise.

Measurements. ${ }^{1} \mathrm{H}$ NMR spectra were recorded on a Varian Inova-500 spectrometer $(500 \mathrm{MHz})$ by using $\mathrm{CDCl}_{3}$ or $\mathrm{C}_{2} \mathrm{D}_{6} \mathrm{SO}$ as a solvent. Size exclusion chromatography (SEC) data was obtained using Viscotek's GPCmax and TDA302 Tetradetector Array system equipped with two PolyPore 
columns (Polymer Labs, Agilent). The detector unit contained a refractive index, UV, viscosity, low angle $\left(7^{\circ}\right)$ and right angle $\left(90^{\circ}\right)$ light scattering modules. Tetrahydrofuran $\left(30^{\circ} \mathrm{C}, 1 \mathrm{~mL} / \mathrm{min}\right)$ was used as the mobile phase. The system was calibrated with 10 linear polystyrene standards from 500 to $1.2 \times 10^{6} \mathrm{~g} / \mathrm{mol}$. SEC analysis in DMF $(0.01 \mathrm{M} \mathrm{LiBr})$ was carried out at $55^{\circ} \mathrm{C}$ on a Viscotek GPC system equipped with a VE-3580 refractive index detector, two mixed bed (PolyAnalytik) organic columns (PAS-103M and PAS-105M). The system was calibrated with 10 linear polystyrene standards from 500 to $1.2 \times 10^{6} \mathrm{~g} / \mathrm{mol}$. UV/vis spectra were measured using an Agilent UV-Vis 8453 spectrophotometer. SEM images were obtained on a Carl Zeiss AURIGA instrument with a $3 \mathrm{kV}$ accelerating voltage and a secondary electron detector. Surfaces of freshly fractured samples were coated with a 1-2 nm thick gold layer prior to imaging. Nitrogen adsorption isotherms were obtained on a Quantachrome NOVA 1200e surface area and pore size analyzer (Boynton Beach, FL, USA) at the temperature of liquid nitrogen (77.3 K). Samples were degassed for $20 \mathrm{~h}$ at room temperature before measurement. Surface area was determined by the Brunauer-Emmet-Teller (BET) method, while pore size and volume were determined by Barrett-Joyner-Halenda (BJH) analysis. Small-angle X-ray scattering measurements were carried out at the 11-BM (CMS) beamline of the National Synchrotron Light Source II (NSLS-II), using an X-ray energy of $13.5 \mathrm{keV}$. The data were collected using Dectris PILATUS $300 \mathrm{~K}$ area detector located approximately $5 \mathrm{~m}$ from the sample center, the sample to detector distance was calibrated using silver behenate.

\section{Example Procedure for Grafting MMA/CMA Side Chains from Poly(GM110-b-BIEM210-b-}

GM90) Triblock Copolymers (B-4). MMA was sparged with nitrogen for 15 min in a septum- 
capped flask to remove oxygen. A three-times excess of a stock solution of $\mathrm{CuCl}(7.2 \mathrm{mg}, 0.072$ mmol), $\mathrm{CuCl}_{2}(0.97 \mathrm{mg}, 7.24 \mu \mathrm{mol})$, and 4,4'-dinonyl-2,2'- bipyridine (dNbp) (65.0 mg, 0.16 mmol) were placed into a dry Schlenk flask equipped with a magnetic stir bar. The flask was sealed with a septum, evacuated, and refilled with nitrogen three times. Deoxygenated MMA $(0.27 \mathrm{~mL})$ was added to the flask. The catalyst mixture was allowed to stir for $2 \mathrm{~h}$ at room temperature until a homogeneous brown catalyst solution was obtained. In a separate Schlenk reaction tube equipped with a stir bar, poly $\left(\mathrm{GM}_{110}-b-\mathrm{BIEM}_{210}-b-\mathrm{GM}_{90}\right)(\mathrm{P}-13)$ triblock copolymer $(60 \mathrm{mg}, 0.15 \mathrm{mmol}$ of $\mathrm{Br})$ and CMA (1.0 g, $3.62 \mathrm{mmol})$ were dissolved in an MMA $(0.5 \mathrm{~mL})$ and anisole $(4.5 \mathrm{~mL})$ mixture. The reaction mixture was then degassed by three cycles of freeze-pump-thaw. Under nitrogen flow, the catalyst mixture was transferred into the reaction tube, and the tube was sealed. The polymerization was performed at $55^{\circ} \mathrm{C}$. After $6.5 \mathrm{~h}$, the reaction was quenched by cooling to room temperature and opening the flask to air. The polymer was precipitated in methanol three times, dried in a vacuum oven overnight and obtained as a white powder $(410 \mathrm{mg})$.

Modification of Epoxide Groups with 4-Pentenoic Acid. Poly(GM110- $b$-(BIEM ${ }_{210}-g-\left(\mathrm{MMA}_{13}-\right.$ $r$-CMA8))-b-GM90) (B-4) (100 mg, $0.024 \mathrm{mmol}$ of oxirane), trimethylamine (10 $\mu \mathrm{L}, 71 \mu \mathrm{mol})$, and 4-pentenoic acid (0.24 mL, $2.4 \mathrm{mmol})$ were dissolved in DMF $(6.5 \mathrm{~mL})$ in a round-bottom flask. The reaction mixture was heated at $90{ }^{\circ} \mathrm{C}$ for $36 \mathrm{~h}$. After the reaction, the solution was concentrated and precipitated in water. A dark yellow product was dissolved in DCM, precipitated in methanol three times, and dried under vacuum overnight to yield a pale yellow powder.

Synthesis of Star-Brush Copolymers by Cross-Metathesis. In a representative procedure, DCM was purged with $\mathrm{N}_{2}$ for $10 \mathrm{~min}$ in a $20 \mathrm{~mL}$ vial before use. 4-Pentenoic acid-modified poly( $\mathrm{GM}_{100-}$ 
$b$-(BIEM $\left.\left.200-g-\left(\mathrm{MMA}_{10}-r-\mathrm{CMA}_{7}\right)\right)\right)(\mathrm{B}-12)(10 \mathrm{mg}, 1.5 \mu \mathrm{mol}$ of olefin) was placed in a $1.5 \mathrm{~mL}$ vial, and purged with $\mathrm{N}_{2}$ for $5 \mathrm{~min}$, and subsequently dissolved in DCM $(0.19 \mathrm{~mL})$. Grubbs' II catalyst $(0.12 \mathrm{mg}, 1.42 \mu \mathrm{mol})$ was placed in a separate vial and purged with $\mathrm{N}_{2}$ for $5 \mathrm{~min}$, then dissolved in $\operatorname{DCM}(10 \mu \mathrm{L})$. The catalyst solution was transferred into the reaction vial, and the cross-linking was carried out at room temperature for $5 \mathrm{~h}$.

Synthesis of Mesoporous Networks by Cross-Metathesis (MPF-11). In a typical procedure, DCM was purged with $\mathrm{N}_{2}$ for $10 \mathrm{~min}$ in a $20 \mathrm{~mL}$ vial before use. 4-Pentenoic acid-modified poly $\left(\mathrm{GM}_{110}-b-\left(\mathrm{BIEM}_{210}-g-\left(\mathrm{MMA}_{13}-r-\mathrm{CMA}_{8}\right)\right)-b-\mathrm{GM}_{90}\right)(\mathrm{B}-4)(30 \mathrm{mg})$ was placed in a $1.5 \mathrm{~mL}$ vial, and purged with $\mathrm{N}_{2}$ for 5 min, and subsequently dissolved in DCM (76 $\left.\mu \mathrm{L}\right)$. Grubbs' II catalyst $(0.6 \mathrm{mg})$ was placed in a separate vial and purged with $\mathrm{N}_{2}$ for $5 \mathrm{~min}$, then dissolved in DCM $(18 \mu \mathrm{L})$. The catalyst solution was transferred into the reaction vial, and the cross-linking was carried out at room temperature for $16 \mathrm{~h}$. After intramolecular cross-linking, DCM was exchanged with DMF and the gel in DMF solvent was exposed to UV light (UVP XX-15L, $15 \mathrm{~W}$ high-pressure mercury lamp) for $2 \mathrm{~h}$. After UV cross-linking, DMF was exchanged with DI water and the sample was left in DI water for $18 \mathrm{~h}$. Then DI water was removed, and the resulting product was dried in a vacuum oven at room temperature.

\section{Acknowledgements}

This work was supported in part by the Donors of the American Chemical Society Petroleum Research Fund (55593-ND7) and by the National Science Foundation (DMR-1409467). The authors would like to thank Professor Luis Colon for the help with nitrogen adsorption analysis. This research used resources of the Center for Functional Nanomaterials and CMS beamline of the 
National Synchrotron Light Source II, a U.S. Department of Energy (DOE) Office of Science User Facilities operated for the DOE Office of Science by Brookhaven National Laboratory under Contract No. DE-SC0012704.

\section{Dedication}

This paper is dedicated to Prof. Marc Hillmyer on the occasion of his 50th birthday.

\section{Supporting Information}

Supporting Information is available free of charge on the ACS Publication website at DOI: 10.1021/acsnano.7b03214.

Experimental details for the synthesis of end-reactive bottlebrush copolymers, SEC, NMR, DSC, SAXS and UV characterization (PDF).

The authors declare no competing financial interest.

\section{References}

(1) Jackson, E. A.; Hillmyer, M. A. Nanoporous Membranes Derived from Block Copolymers: From Drug Delivery to Water Filtration. ACS Nano 2010, 4, 3548-3553.

(2) Lu, G. Q.; Zhao, X. S., Nanoporous Materials: Science and Engineering. Imperial College Press: London, 2004.

(3) Davis, M. E. Ordered Porous Materials for Emerging Applications. Nature 2002, 417, 813821.

(4) Kreno, L. E.; Leong, K.; Farha, O. K.; Allendorf, M.; Van Duyne, R. P.; Hupp, J. T. MetalOrganic Framework Materials as Chemical Sensors. Chem. Rev. 2012, 112, 1105-1125.

(5) Adiga, S. P.; Jin, C.; Curtiss, L. A.; Monteiro-Riviere, N. A.; Narayan, R. J. Nanoporous Membranes for Medical and Biological Applications. Wiley Interdiscip. Rev. Nanomed. Nanobiotechnol. 2009, 1, 568-581. 
(6) Furukawa, H.; Cordova, K. E.; O’Keeffe, M.; Yaghi, O. M. The Chemistry and Applications of Metal-Organic Frameworks. Science 2013, 341, 1230444.

(7) Eddaoudi, M.; Kim, J.; Rosi, N.; Vodak, D.; Wachter, J.; Keeffe, M.; Yaghi, O. M. Systematic Design of Pore Size and Functionality in Isoreticular Mofs and Their Application in Methane Storage. Science 2002, 295, 469-472.

(8) Diercks, C. S.; Yaghi, O. M. The Atom, the Molecule, and the Covalent Organic Framework. Science 2017, 355, eaal1585.

(9) McKeown, N. B.; Budd, P. M. Polymers of Intrinsic Microporosity (Pims): Organic Materials for Membrane Separations, Heterogeneous Catalysis and Hydrogen Storage. Chem. Soc. Rev. 2006, 35, 675-683.

(10) Sheiko, S. S.; Sumerlin, B. S.; Matyjaszewski, K. Cylindrical Molecular Brushes: Synthesis, Characterization, and Properties. Prog. Polym. Sci. 2008, 33, 759-785.

(11) Verduzco, R.; Li, X.; Peseka, S. L.; Steinc, G. E. Structure, Function, Self-Assembly, and Applications of Bottlebrush Copolymers. Chem. Soc. Rev. 2015, 44, 2405-2420.

(12) Rathgeber, S.; Pakula, T.; Wilk, A.; Matyjaszewski, K.; Lee, H. I.; Beers, K. L. BottleBrush Macromolecules in Solution: Comparison between Results Obtained from Scattering Experiments and Computer Simulations. Polymer 2006, 47, 7318-7327.

(13) Huang, K.; Canterbury, D. P.; Rzayev, J. Organosoluble Polypyrrole Nanotubes from CoreShell Bottlebrush Copolymers. Chem. Commun. 2010, 46, 6326-6328.

(14) Huang, K.; Rzayev, J. Well-Defined Organic Nanotubes from Multicomponent Bottlebrush Copolymers. J. Am. Chem. Soc. 2009, 131, 6880-6885.

(15) Onbulak, S.; Rzayev, J. Cylindrical Nanocapsules from Photo-Cross-Linkable Core-Shell Bottlebrush Copolymers. Polym. Chem. 2015, 6, 764-771.

(16) Daniel, W. F.; Burdynska, J.; Vatankhah-Varnoosfaderani, M.; Matyjaszewski, K.; Paturej, J.; Rubinstein, M.; Dobrynin, A. V.; Sheiko, S. S. Solvent-Free, Supersoft and Superelastic Bottlebrush Melts and Networks. Nat. Mater. 2016, 15, 183-189.

(17) Pakula, T.; Zhang, Y.; Matyjaszewski, K.; Lee, H.-i.; Boerner, H.; Qin, S.; Berry, G. C. Molecular Brushes as Super-Soft Elastomers. Polymer 2006, 47, 7198-7206.

(18) Wu, D.; Nese, A.; Pietrasik, J.; Liang, Y.; He, H.; Kruk, M.; Huang, L.; Kowalewski, T.; Matyjaszewski, K. Preparation of Polymeric Nanoscale Networks from Cylindrical Molecular Bottlebrushes. ACS Nano 2012, 6, 6208-6214.

(19) Trenor, S. R.; Shultz, A. R.; Love, B. J.; Long, T. E. Coumarins in Polymers: From Light Harvesting to Photo-Cross-Linkable Tissue Scaffolds. Chem. Rev. 2004, 104, 3059-3077. 
(20) Moad, G.; Rizzardo, E.; Thang, S. H. Living Radical Polymerization by the RAFT Process. Aust. J. Chem. 2005, 58, 379-410.

(21) Altay, E.; Rzayev, J. Synthesis of Star-Brush Polymer Architectures from End-Reactive Molecular Bottlebrushes. Polymer 2016, 98, 487-494.

(22) Beers, K. L.; Gaynor, S. G.; Matyjaszewski, K.; Sheiko, S. S.; Moller, M. The Synthesis of Densely Grafted Copolymers by Atom Transfer Radical Polymerization. Macromolecules 1998, 31, 9413-9415.

(23) Matyjaszewski, K.; Xia, J. H. Atom Transfer Radical Polymerization. Chem. Rev. 2001, 101, 2921-2990.

(24) Hoveyda, A. H.; Zhugralin, A. R. The Remarkable Metal-Catalysed Olefin Metathesis Reaction. Nature 2007, 450, 243-251.

(25) Vougioukalakis, G. C.; Grubbs, R. H. Ruthenium-Based Heterocyclic Carbene-Coordinated Olefin Metathesis Catalysts. Chem. Rev. 2010, 110, 1746-1787.

(26) Scholl, M.; Ding, S.; Lee, C. W.; Grubbs, R. H. Synthesis and Activity of a New Generation of Ruthenium-Based Olefin Metathesis Catalysts Coordinated with 1,3-Dimesityl-4,5-

Dihydroimidazol-2-Ylidene Ligands. Org. Lett. 1999, 1, 953-956.

(27) Sing, K. The Use of Nitrogen Adsorption for the Characterisation of Porous Materials. Colloids Surf., A 2001, 187-188, 3-9.

(28) Robbins, S. W.; Beaucage, P. A.; Sai, H.; Tan, K. W.; Werner, J. G.; Sethna, J. P.; DiSalvo, F. J.; Gruner, S. M.; Van Dover, R. B.; Wiesner, U. Block Copolymer Self-Assembly-Directed Synthesis of Mesoporous Gyroidal Superconductors. Sci. Adv. 2016, 2, e1501119.

(29) Zalusky, A. S.; Olayo-Valles, R.; Wolf, J. H.; Hillmyer, M. A. Ordered Nanoporous Polymers from Polystyrene-Polylactide Block Copolymers. J. Am. Chem. Soc. 2002, 124, 1276112773.

(30) Ilavsky, J.; Jemian, P. R. Irena: Tool Suite for Modeling and Analysis of Small-Angle Scattering. J. Appl. Crystallogr. 2009, 42, 347-353.

(31) Zhang, B.; Grohn, F.; Pedersen, J. S.; Fischer, K.; Schmidt, M. Conformation of Cylindrical Brushes in Solution: Effect of Side Chain Length. Macromolecules 2006, 39, 8440-8450.

(32) Seo, M.; Hillmyer, M. A. Reticulated Nanoporous Polymers by Controlled PolymerizationInduced Microphase Separation. Science 2012, 336, 1422-1425.

(33) Hillmyer, M., Nanoporous Materials from Block Copolymer Precursors. In Block Copolymers II, Abetz, V., Ed. Springer Berlin / Heidelberg: 2005, Vol. 190, pp 137-181. 
(34) Orilall, M. C.; Wiesner, U. Block Copolymer Based Composition and Morphology Control in Nanostructured Hybrid Materials for Energy Conversion and Storage: Solar Cells, Batteries, and Fuel Cells. Chem. Soc. Rev. 2011, 40, 520-535.

(35) Ling, J.; Rong, M. Z.; Zhang, M. Q. Coumarin Imparts Repeated Photochemical Remendability to Polyurethane. J Mater Chem 2011, 21, 18373-18380.

(36) Jiang, J. Q.; Qi, B.; Lepage, M.; Zhao, Y. Polymer Micelles Stabilization on Demand through Reversible Photo-Cross-Linking. Macromolecules 2007, 40, 790-792. 
Table of Contents graphic

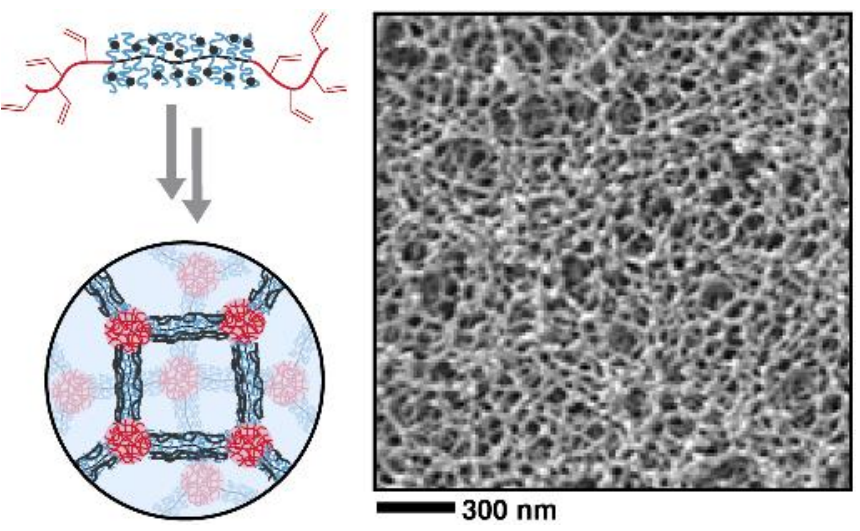

